\title{
FORMULASI KRIM BERBAHAN AKTIF MINYAK KAPULAGA (AMOMUM COMPACTUM SOLAND.) SEBAGAI ANTIBAKTERI STAPHYLOCOCCUS AUREUS
}

\author{
Lilis Pania Anugrah, Laode Rijai, Wisnu Cahyo Prabowo \\ Laboratorium Penelitian dan Pengembangan Kefarmasian "Farmaka Tropis", \\ Fakultas Farmasi, Universitas Mulawarman, Samarinda, Indonesia \\ *Email: Lilis.p.anugrah@gmail.com
}

\begin{abstract}
Essential oils or volatile oils, it is known that Cardamom (Amomum compactum Soland.) Is one of the plants containing essential oils of cineol, terpineol and borneol. Cardamom oil functions as an antibacterial. The aim of this study was to determine the yield content of cardamom oil, cream base formula optimization, and to determine the antibacterial activity of cardamom oil. The research method used is steam distillation cardamom oil, and antibacterial testing, namely order diffusion disc method. The results showed that the yield of cardamom oil obtained from steam distillation was $4.867 \%$. The evaluation results of cream preparations with different concentrations of stearic acid FI (8\%) and FII (7\%) include organoleptic (white color, distinctive oil odor, semisolid form), homogeneity, and dispersion in FI $(6.3 \mathrm{~cm})$ and FII $(4.725 \mathrm{~cm}), \mathrm{pH} \mathrm{FI}(8,00)$ and FII $(7,43)$ and viscosity FI $(30,72842 \mathrm{~Pa} . \mathrm{s})$ and FII $(61,69424 \mathrm{~Pa} . \mathrm{s})$. The results of antibacterial activity in cardamom oil, that the best concentration is $15 \%$ with clear zones of 10,883 mm.
\end{abstract}

Keyword: Cardamom (Amomum compactum Soland.) And Antibacterials

\begin{abstract}
ABSTRAK
Minyak atsiri atau minyak yang mudah menguap, telah diketahui bahwa Kapulaga (Amomum compactum Soland.) merupakan salah satu tanaman yang mengandung minyak atsiri sineol, terpineol dan borneol. Minyak kapulaga berfungsi sebagai antibakteri. Penelitian ini bertujuan untuk mengetahui kadar rendemen minyak kapulaga, formula basis krim, dan untuk mengetahui aktivitas antibakteri minyak kapulaga. Metode penelitian yang digunakan minyak kapulaga destilasi uap, dan pengujian antibakteri yaitu difusi agar metode cakram. Hasil penelitian menunjukkan bahwa rendemen minyak kapulaga yang diperoleh dari destilasi uap 4,867\%. Hasil evaluasi sediaan krim dengan konsentrasi asam stearat yang berbeda FI (8\%) dan FII (7\%) antara lain organoleptis (Warna putih, bau khas minyak, bentuk semipadat), homogenitas, dan daya sebar pada FI $(6,3 \mathrm{~cm})$ dan FII $(4,725$ $\mathrm{cm})$. pH krim FI $(8,00)$ dan FII $(7,43)$ dan viskositas FI $(30,72842$ Pa.s) dan FII $(61,69424$ Pa.s). Hasil aktivitas antibakteri pada minyak kapulaga, bahwa konsentrasi terbaik $15 \%$ dengan zona bening $10,883 \mathrm{~mm}$.
\end{abstract}

Kata Kunci: Kapulaga (Amomum compactum Soland.) dan Antibakteri 
DOI: https://doi.org/10.25026/mpc.v8i1.303

\section{PENDAHULUAN}

Bakteri Staphylococcus aureus merupakan bakteri flora normal pada kulit dan selaput lendir pada manusia. Staphylococcus dapat menjadi penyebab infeksi baik pada manusia maupun hewan. Bakteri $S$. aureus dapat mengakibatkan infeksi kerusakan pada kulit atau luka pada organ tubuh jika bakteri ini mengalahkan mekanisme pertahanan tubuh. Saat bakteri masuk ke peredaran darah bakteri dapat menyebar ke orang lain dan menyebabkan infeksi. Hampir setiap organ akan mengalami beberapa tipe infeksi dari $S$. aureus, infeksi tersebut bervariasi mulai dari keracunan, infeksi kulit ringan seperti jerawat dan bisul, sampai infeksi berat seperti meningitis, osteomyelitis, pneumonia dan mastitis [4]. Penyumbatan terjadi disebabkan oleh salah satu bakteri penyebab terjadinya jerawat yaitu Staphylococcus aureus sehingga terjadi peradangan [3].

Kapulaga (Amomum compactum Soland.) merupakan salah satu tanaman rempah yang dihasilkan oleh Indonesia yang juga merupakan komoditas ekspor. Penyulingan biji diperoleh minyak atsiri yang disebut Oleum Cardamomi yang digunakan sebagai stimulus dan pemberi aroma Pemanfaatan kapulaga dalam bentuk minyak atsiri dapat digunakan sebagai bahan aromatik, mengobati batuk, bau mulut, dan gatal pada tenggorokan sedangkan buah keringnya biasa digunakan sebagai bahan tambahan untuk penyedap masakan, kue, serta obatobatan penghilang rasa sakit [8].

Biji kapulaga yang diambil dari tumbuhan sebelum buah masak dapat dimanfaatkan sebagai obat. Di dalam biji kapulaga terkandung minyak atsiri sebesar 3-7\% yang terdiri atas sineol, borneol, dan terpineol [1]. Biji kapulaga mengandung terpineol, terpineol asetat, sineol, borneol, dan kamfer yang berkhasiat mengencerkan dahak, memudahkan pengeluaran air dari darah, menghilangkan rasa sakit, mengharumkan, stimulan dan pemberi aroma. Selain itu, kapulaga juga mengandung zat putih telur, kalsium oksalat dan silisum.

Krim merupakan suatu sediaan semisolid berisi satu atau lebih bahan obat yang terlarut atau terdispersi dalam fase air dalam bentuk emulsi minyak (A/M) atau minyak dalam air (M/A) atau tipe lain dengan basis yang dapat dicuci dengan air. Sediaan krim umumnya digunakan secara topikal pada kulit dan digunakan pula pada membran mukosa, seperti pada rekal. Krim lebih dipilih karena lebih mudah dioleskan dan mudah untuk dibilas dimana krim dengan tipe minyak dalam air (M/A) lebih mudah dibilas daripada tipe air dalam minyak (A/M) [2].

Penelitian ini bertujuan untuk mengetahui kadar randemen minyak kapulaga (Amomum compactum Soland.), untuk mengetahui formula basis krim, dan untuk mengetahui minyak kapulaga memiliki aktivitas antibakteri terhadap bakteri Staphylococcus aureus.

\section{METODE PENELITIAN}

\section{Alat dan Bahan}

Alat yang digunakan adalah timbangan analitik, destilasi uap, gelas kimia, erlemenyer, cawan porselin, mortir dan stamper, hot plate, gelas ukur, alat pengukuran $\mathrm{pH}$-meter, alat pengukuran viskometer rheosys, alat uji daya sebar, autoklaf, cawan petri, tabung reaksi, LAF, Bunsen, ose bulat, inkubator.

Bahan yang digunakan adalah bakteri Staphylococcus aureus, aquades, nutrien 
agar (NA), asam stearat, trietanolamin, setil alkohol, paraffin cair, dan gliserin.

\section{Pembuatan Minyak kapulaga}

Biji kapulaga diambil sebanyak 300 gram dan diblender lalu dimasukkan ke dalam alat destilasi uap dan air selama 45 jam. Minyak yang diperoleh ditampung ke dalam gelas kimia, disimpan dalam botol vial dan dihitung kadar rendemen.

\section{Pembuatan Medium NA (Nutrien agar)}

Dimasukkan kedalam erlenmenyer sebanyak 15 gram NA (Nutrien agar) dilarutkan dalam aquades steril sebanyak $500 \mathrm{ml}$, kemudian dihomogenkan dan dipanaskan diatas hot plate hingga semua larut. Kemudian disterilkan di dalam autoclave pada suhu $121^{\circ} \mathrm{C}$ selama 15 menit. Kemudian didinginkan dan siap digunakan.

\section{Pembuatan Stok Bakteri Uji}

Disiapkan taabung reaksi steril yang diisi dengan medium NA. Kemudian satu koloni bakteri Staphylococcus aureus diambil dengan ose bulat steril, lalu diinokulasikan pada permukaan media dengan cara menggores secara zig-zag, kemudian diinkubasikan pada suhu $37^{\circ} \mathrm{C}$ selama 24 jam didalam inkubator dan disimpan didalam freezer.

\section{Peremajaan Bakteri}

Peremajaan bakteri uji dilakukan dengan cara menggoreskan secara zig-zag satu sampai empat ose bakteri yang diambil dari stok bakteri uji ke dalam medium agar miring dalam tabung reaksi yang telah dibuat sebelumnya.Selanjutnya diinkubasikan pada suhu $37^{\circ} \mathrm{C}$ selama $1 \times 24$ jam didalam inkubator.

\section{Pembuatan Suspensi Bakteri}

Bakteri uji dibuat dalam bentuk suspensi bakteri. Pembuatan suspensi bakteri dilakukan dengan menambahkan 9 ml larutan $\mathrm{NaCl} 0,9 \%$ kedalam tabung reaksi berisi hasil peremajaan bakteri, dan di homogenkan. Dengan perbandingan 1:40, dari suspensi pertama diambil 2,5 $\mathrm{ml}$ dimasukkan ke dalam tabung reaksi yang baru, lalu dimasukkan larutan $\mathrm{NaCl}$ 7,5 ml dan dihomogenkan. Kemudian siap di gunakan.

\section{Uji Difusi Agar Metode Cakram}

Biakan bakteri Staphylococcus aureus diambil $1 \mathrm{ml}$ lalu ditambahkan medium NA yang masih hangat sebanyak $10 \mathrm{ml}$ dimasukkan ke dalam cawan petri kemudian dihomogenkan dan dibiarkan memadat, lalu paper disk yang telah direndam pada masing-masing kosentrasi minyak selama 15 menit ditempelkan pada medium, lalu diinkubasi pada suhu $37^{\circ} \mathrm{C}$ selama 24 jam. Pengukuran zona bening yang menggunakan jangka sorong.

\section{Optimasi Formula Basis Krim}

Krim dibuat dengan cara meleburkan berturut-turut fase minyak (asam stearat, setil alkohol, dan paraffin cair) di atas hotplate pada suhu $50^{\circ} \mathrm{C}$. Pada cawan porselin lain, trietanolamin dalam aquades dan dipanaskan hingga suhu $70^{\circ} \mathrm{C}$. Fase minyak dimasukkan kedalam mortir lalu digerus, kemudian ditambahkan fase minyak dan gliserin sedikit demi sedikit lalu digerus sampai homogen. Setelah terbentuk basis krim kemudian dimasukkan ke dalam wadah.

\section{Pengujian Organoleptik}

Dilakukan dengan mengamati bau, warna dan penampilan bentuk dari sediaan krim yang dibuat dengan menggunakan panca indera untuk mengetahui krim yang dibuat sesuai dengan warna, bau dan bentuk dari minyak yang digunakan.

\section{Pengujian Homogenitas}

Dilakukan dengan mengambil 1 gram sediaan dan diletakkan pada bagian atas, tengah dan bawah kemudian dioleskan pada sekeping kaca transparan kemudian diamati jika terjadi pemisahan fase atau 
terdapat bagian yang tercampur dengan baik.

\section{Pengujian pH}

Pengujian $\mathrm{pH}$ pada sediaan dilakukan dengan menggunakan $\mathrm{pH}$-meter. Uji $\mathrm{pH}$ dapat dilakukan dengan menimbang 1 gram sediaan uji dan diencerkan dengan 5 $\mathrm{ml}$ aquades. pH-meter kemudian dimasukkan ke dalam sediaan uji dan dibaca nilai $\mathrm{pH}$ yang tertera pada monitor $\mathrm{pH}$-meter.

\section{Pengujian Viskositas}

Dilakukan dengan viskometer rheosys pada kecepatan 13 rpm. Pengamatan viskositas dilakukan selama 4 minggu setiap 1 minggu sekali. Sediaan dilakukan baik jika berada pada rentang 2-50 P.a.s.

\section{Pengujian Daya Sebar}

Dilakukan dengan meletakkan krim diantara dua kaca transparan yang diletakkan diatas milimeter blok. Peningkatan sebaran krim akibat. Penambahan berat beban 150 gram, kemudian dicatat sebagai data setelah 1 menit daya sebar.

\section{HASIL DAN PEMBAHASAN}

$$
\text { Rendemen } \begin{aligned}
(\%) & =\frac{\text { berat minyak yang diperoleh }(\mathrm{g})}{\text { berat sampel segar }(\mathrm{g})} \times 100 \% \\
& =\frac{14,6 \text { gram }}{300 \text { gram }} \times 100 \% \\
& =4,8666666667 \%
\end{aligned}
$$

Tabel 1.Formulasi krim bahan aktif minyak Kapulaga

\begin{tabular}{ccc}
\hline \multirow{2}{*}{ Bahan } & \multicolumn{2}{c}{ Formula (m/a) } \\
\cline { 2 - 3 } & FI & FII \\
\hline Asam stearat & $8 \mathrm{gr}$ & $7 \mathrm{gr}$ \\
Trietanolamin & $2 \mathrm{gr}$ & $2 \mathrm{gr}$ \\
Setil alkohol & $2 \mathrm{gr}$ & $2 \mathrm{gr}$ \\
Paraffin cair & $2 \mathrm{gr}$ & $3 \mathrm{gr}$ \\
Gliserin & $10 \mathrm{gr}$ & $10 \mathrm{gr}$ \\
Aquades & Ad 50 & Ad 50 \\
\hline
\end{tabular}

Tabel 2. Hasil evaluasi basis krim

\begin{tabular}{cll}
\hline \multirow{2}{*}{ Pemeriksaan } & \multicolumn{2}{c}{ FI } \\
\cline { 2 - 3 } Organoleptis & Warna putih, bau khas minyak, & Warna putih, bau khas minyak, \\
& bentuk semipadat & bentuk semipadat \\
Homogenitas & Butiran-butiran & Homogen \\
Daya sebar & $6,3 \mathrm{~cm}$ & $4,725 \mathrm{~cm}$ \\
pH & 8,00 & 7,43 \\
Viskositas & 30,72842 Pa.s & 61.69424 Pa.s \\
\hline
\end{tabular}


Tabel 3. Bakteri Staphylococcus aureus

\begin{tabular}{cc}
\hline Zat uji (Minyak Kapulaga) & Diameter Penghambatan \\
\hline $5 \%$ & $8,876 \mathrm{~mm}$ \\
$10 \%$ & $9,729 \mathrm{~mm}$ \\
$15 \%$ & $10,883 \mathrm{~mm}$ \\
$20 \%$ & $9,660 \mathrm{~mm}$ \\
\hline
\end{tabular}

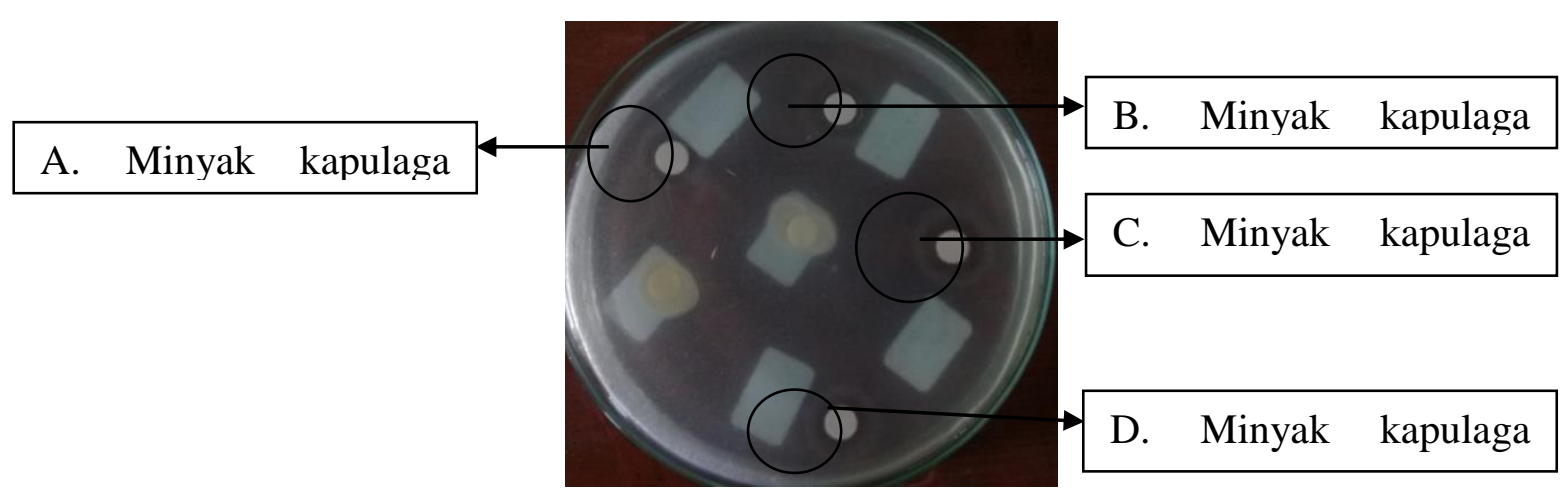

Gambar 1. Bakteri Staphylococcus aureus

Minyak kapulaga (Amomum compactum Soland.) dengan metode destilasi uap menggunakan pelarut aquades. Hasil minyak kapulaga yang diperoleh sebanyak 14,6 gram dengan hasil rendemen $4,867 \%$. Sementara yang ada, kadar minyak atsiri kapulaga adalah $3-7 \%$ [1].

Hasil pengamatan pengujian organoleptis krim menunjukkan sediaan krim memiliki bentuk yang setengah padat atau semipadat dan memiliki bau yang khas minyak. Untuk warna sediaan krim berwarna putih layaknya warna krim.

Uji homogenitas bertujuan untuk mengetahui tercampurnya bahan-bahan sediaan krim. Hasil uji homogenitas menunjukkan bahwa sediaan krim dari FI tidak homogen terjadi adanya butiranbutiran saat digosokkan pada tangan, sedangkan FII telah homogen.

Pengujian daya sebar merupakan pengujian yang dilakukan untuk mengetahui kemampuan penyebaran krim. Persyaratan daya sebar untuk sediaan topikal yaitu sekitar $5-7 \mathrm{~cm}$ menunjukkan konsistensi semisolid yang sangat nyaman dalam penggunaan [5]. Berdasarkan uji daya sebar dari sediaan krim dapat disimpulkan bahwa sediaan krim untuk FI memenuhi rentang persyaratan sedangkan FII berada pada rentang 4,725 $\mathrm{cm}$, tidak masuk dalam rentang persyaratan.

Uji pH bertujuan mengetahui keamanan sediaan krim saat digunakan sehingga tidak mengiritasi kulit. Pengukuran $\mathrm{pH}$ untuk mengetahui apakah krim yang telah dibuat bersifat asam atau basa, sedangkan $\mathrm{pH}$ kulit wajah memiliki kriteria yaitu sekitar 4,5-6,5 [9]. Hasil pengukuran $\mathrm{pH}$ yang diperoleh pada sediaan krim FI dan FII tidak sesuai dengan pH kulit yang seharusnya 4,5-6,5. Akan tetapi $\mathrm{pH}$ yang dimiliki FI tersebut berada $\mathrm{pH}$ yang bersifat basa $(\mathrm{pH}>7)$ sedangkan $\mathrm{pH}$ yang dimiliki FII masih berada pada kisaran $\mathrm{pH}$ netral ( $\mathrm{pH} 7)$.

Pengujian viskositas sediaan krim berdasarkan hasil pengamatan yaitu krim yang memenuhi persyaratan viskositas krim adalah FI (30,72842 Pa.s). Persyaratan sediaan krim dikatakan baik jika viskositas berada pada rentang 2-50 Pa.s [7]. 
Kriteria kekuatan daya antibakteri sebagai berikut: diameter zona hambat 5 $\mathrm{mm}$ atau kurang dikategorikan lemah, zona hambat 5-10 $\mathrm{mm}$ dikategorikan sedang, zona hambat $10-20 \mathrm{~mm}$ dikategorikan kuat dan zona hambat 20 $\mathrm{mm}$ atau lebih dikategorikan sangat kuat [6]. Hasil pengujian aktivitas antibakteri minyak kapulaga dengan menggunakan metode difusi paper disk menunjukkan bahwa minyak kapulaga dengan variasi konsentrasi masing-masing memiliki aktivitas antibakteri terbentuk adanya zona bening, nilai diameter zona hambat dari konsentrasi $5 \% \quad(8,876 \mathrm{~mm}), 10 \%$ $(9,729 \mathrm{~mm}), 15 \%(10,883 \mathrm{~mm})$, dan $20 \%$ (9,660 mm).

\section{KESIMPULAN}

Minyak kapulaga dengan menggunakan destilasi uap dengan rendemen minyak yang diperoleh adalah 4,867\%. Optimasi formula basis krim pada dengan perbedaan konsentrasi asam stearat FI (8\%) dan FII (7\%) dengan evaluasi sediaan krim yaitu organoleptis (Warna putih, bau khas minyak, bentuk semipadat), homogenitas, daya sebar pada FI $(6,3 \mathrm{~cm})$ dan FII $(4,725 \mathrm{~cm}), \mathrm{pH}$ FI $(8,00)$ dan FII $(7,43)$ dan viskositas FI (30,72842 Pa.s) dan FII (61,69424 Pa.s). Optimasi basis yang stabil pada FII (7\%) yang memenuhi persyaratan. Minyak kapulaga dengan uji bakteri Staphylococcus aureus dengan terbentuknya zona bening, nilai diameter zona hambat dari konsentrasi $15 \%$ $(10,883 \mathrm{~mm})$ bahwa zona hambat $10-20$ mm dikategorikan kuat.

\section{DAFTAR PUSTAKA}

[1] Agoes, A., (2010), Tanaman Obat Indonesia $3^{\text {rd }}$ ed, Salemba Medika, Jakarta.
[2] Ansel, Howard C. 2005. Pengantar Bentuk Sediaan Farmasi (terjemahan Farida Ibrahim). Edisi $V$. Universitas Indonesia Press. Jakarta.

[3] Ayu, S. (2009). Cara Ampuh Mengobati Jerawat, Buana Pustaka, Yogyakarta

[4] Bota, W. ( 2015), Potensi Senyawa Minyak Sereh Wangi (Citronella Oil) Dari Tumbuhan Cymbopogon nardus L. Sebagai Agen Antibakteri, Jurnal Seminar Nasional Sains dan Teknologi

[5] Genatrika, E. (2016), Formulasi Sediaan Krim Minyak Jintan Hitam (Nigella sativa L.) Sebagai Antijerawat Terhadap Bakteri Propionibacterium acne. Jurnal Pharmacy Vol. 13

[6] Rastina. 2015. Aktivitas Antibakteri Ekstrak Etanol Daun Kari (Murraya koenigii) Terhadap Staphylococcus aureus, Escherichia coli, dan Pseudomonas sp. Jurnal Kedokteran Hewan Vol. 9 No.

[7] Shafira, U., Gadri, A., Lestari, F. 2015. Formulasi sediaan spray gel serbuk getah tanaman jarak cina dengan variasi jenis polimer pembentuk film dan jenis plasticizer. Prosiding Penelitian. Unisba 2015. Bandung

[8] Tambunan, L. (2017). Isolasi dan Identifikasi Komposisi Kimia Minyak Atsiri dari Biji Tanaman Kapulaga (Amomum cardamomum Willd). Jurnal Kimia Riset, Vol. 2 No. 1

[9] Tranggono, R.I., (2007). Buku Ilmu Pengetahuan Kosmetik. PT. Gramedia Pustaka Utama, Jakarta 